\title{
Estimation of unsaturated flow parameters and hysteresis curve from field instrumentation
}

\author{
Asif Ahmed ${ }^{1, *}$, Md Jobair Bin Alam², Pratibha Pandey ${ }^{3}$, and MD Sahadat Hossain ${ }^{4}$ \\ ${ }^{1}$ SUNY Polytechnic Institute, College of Engineering, 100 Seymour Road, Utica, NY 13502, USA \\ ${ }^{2}$ Prairie View A\&M University, Civil Engineering Department, 100 University Drive, Prairie View, TX 77446, USA \\ ${ }^{3}$ University of Texas at Arlington, Civil Engineering Department, 416 Yates Street, Arlington, TX 76019, USA \\ ${ }^{4}$ University of Texas at Arlington, Civil Engineering Department, 416 Yates Street, Arlington, TX 76019, USA
}

\begin{abstract}
The negative pore water pressure or soil suction has significant effect on the performance of geotechnical infrastructures (e.g., slope, pavement, embankment etc.). The unsaturated behavior of soil is not static, rather offers variation in response to climatic loading. The objective of the study was to evaluate field-based techniques of SWCC construction in terms of capturing these variation as compared to laboratory methods and predictive models. The field assessment could allow the quantification of hysteresis effect on the SWCC. Instrumentation data from one Texas, USA highway was used in this study. Soil Water Characteristic Curves (SWCCs) were regenerated utilizing co-located moisture and suction data from the field. Laboratory and field measured SWCCs from the instrumented site were fitted by van Genuchten model. Previously developed predicted models were also utilized to evaluate the SWCC parameters. Based on the evapotranspiration and rainfall amounts, distinct drying and wetting cycles were recorded. Though hourly data was collected in this study, average daily values were used for the analysis. Unsaturated flow parameters $(\alpha, \mathrm{n}, \mathrm{m})$ were determined from both laboratory testing and field moisture-suction data along with the predictive models. Clear differences were observed between the values obtained from predictive models and field generated SWCC. The outcome from this study revealed that field reconstructed SWCCs can be used to simulate higher precision in numerical modeling in numerous geotechnical applications.
\end{abstract}

\section{Introduction}

The soil which supports transportation infrastructures is unsaturated in most of the cases (Gupta et al. 2007 [1]). The majority of the earthen structures are also comprised of unsaturated type soils (Fredlund 1996 [2]). The soil in unsaturated conditions is frequently subjected to change in stress state due to transient wetting and drying climatic conditions (Fredlund \& Rahardjo 1993 [3]; Rahardjo et al. 2019 [4]), the impact of which is reflected on the performance of structures over time. As such, an improved understanding of the unsaturated soil parameters is required in order to assess the long term performance of the pavement and other civil infrastructres.

In unsaturated soil mechanics, the transient seepage is governed by varying hydraulic gradient and coefficient of permeability unlike the steady state condition. The flow rate depends on the induced negative pore water pressure or matric suction which alters with the change in soil moisture. Soil water characteristic curve (SWCC), an important relation in the field of unsaturated soil mechanics describes a correlation between matric suction and moisture content within the soil mass (Fredlund \& Rahardjo 1993 [3]; Lu \& Likos 2004 [5]; Lu et al. 2010 [6]). Moreover, water movement inside the soil depends on the slope of the SWCC curve. Several empirical models have also been proposed to estimate the permeability function using SWCC (Fredlund et al. 1994 [7]). Proper estimation of SWCC is very crucial for a better accuracy of any modeling attempt such as flow and seepage analysis. Although accurate measurement of SWCC is generally required; it is often rather estimated through mathematical functions which could lead to weak interpretation of soil behavior.

Behavior of expansive subgrade is altered by the moisture and suction distribution after precipitation events. To accurately determine the suction distribution in the subgrade through numerical modeling, it is required to provide the correct SWCC parameters. There are several methods of determining SWCC in the laboratory including pressure plates, filter paper method etc. However, due to time and labor constraint, analytic and predictive models have been developed in the past two decades. However, these models are rarely evaluated against the field moisture-suction measurement. Unlike the controlled laboratory setup, field data has the capactiy to capture real-time soil behavior by incorporating the climatic variations- wetting and drying cycles in its measurement. Consequently, the field

\footnotetext{
${ }^{*}$ Corresponding author: asif.ahmed@sunypoly.edu
} 
generated SWCCs are not unique as generated in the laboratory rather is characterized by hysteresis.

Predictive models offer a quick way of determining the SWCC parameters based on the basic soil properties. However, the accuracy of the predictive models are always in question as it incorporates only a few soil properties like percent finer, plasticity index etc. As predictive models always provide an approximation of the results and field instrumentation capture the real time suction-moisture relationship, it would be interesting to check the differenes observed from these two different aprroaches.

Previous researchers have attempted to evaluate the SWCC parameters based on field instrumentation (Bordoni et al. 2017 [8]; Jabro et al. 2009 [9], Al Yahyai 2006 [10]) with some limitations. Bordoni et al. (2017) [8] determined SWCCs in different seasons of the year and reported variations of the unsaturated paramters. The authors' installation depth was limited. In addition, other researchers were mainly focused on the hydrological and agricultural application. As such, there is enough room for development in this topic for geotechnical field.

Therefore, this study evaluates the performance of five predictive models based on the basic index properties of insitu soil and determines the correponding van Genuchten and Fredlund and Xing parameters. Moreover, the field obtained moisture-suction data are analysed for hysteresis. The upper and lower bound SWCC indicating desorption and absorption are identified from field and the correponding unsaturated parameters are determined. The results from predictive models and field are compared. Finally, it is concluded that field measurement has better capability in capturing SWCC variation for numerical modeling.

\section{Material and Methods}

\subsection{Field Instrumentation}

\subsubsection{Site description}

The test site for the current study was located in Lancaster, Texas at State Highway SH 342 (Fig. 1) which consists of high-plasticity clayey soil $(\mathrm{CH})$. The site falls in the semiarid region and experiences average cumulative yearly rainfall of $680 \mathrm{~mm}$ and temperature as high as $100^{\circ} \mathrm{F}$ during dry period. The pavement was found to experience significant edge drop owing to cyclic swelling and shrinkage of expansive subgrade soil, and thus was selected for the study. The side slopes are covered with grasses and dense trees. As a part of the study, the side slope of the pavement was instrumented with series of sensors at different depths to observe seasonal moisture and suction fluctuation over time. One tipping bucket rain gauge was also installed to record precipitation events.

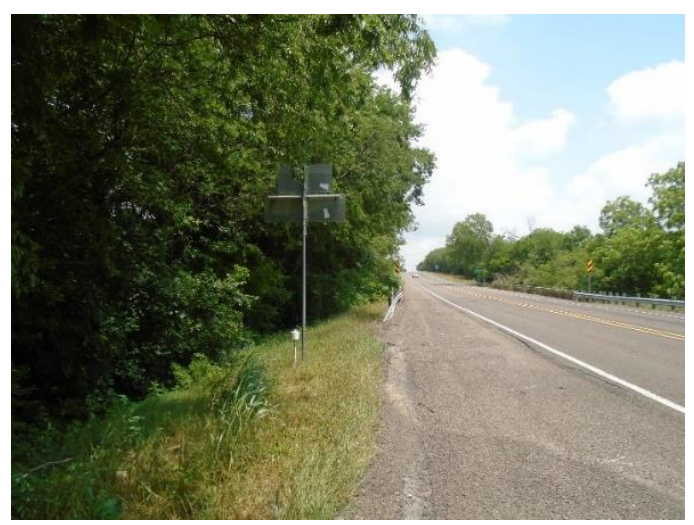

Fig. 1. Selected location for the current study, SH 342 near Dallas, Texas, USA

\subsubsection{Geology of the Site}

The review of geological maps from United States Geological Survey indicates the site to be located in Austin chalk formation of Cretaceous period. This type of formation consists of thin-bedded marl within interbeds of massive chalk (Dawson \& Reaser 1990 [11]). USGS reports thickness of Austin chalk varying in between 300-500 feet. In general, the lower regions of Austin chalk have traces of high shale content which increases with depth (Abdi 2014 [12]). The weathered soils from Austin chalk usually have swell-shrink potential at residual state.

\subsubsection{Soil properties}

Soil sampling was performed to assess the properties of insitu soil. The laboratory investigations were conducted following American Society for Testing and Materials (ASTM) standards. The tests indicated the soil to be highly plastic in nature with plasticity index in between 28 to $42 \%$. The particle size distribution showed more than $85 \%$ fines in the collected soil sample. Average saturated hydraulic conductivity was found to be $2.6 \times 10^{-8} \mathrm{~m} / \mathrm{sec}$ from a depth of $2 \mathrm{~m}$.

\subsubsection{Instrumentation details}

Six moisture sensors and two suction sensors were installed in total at the side slope of SH 342. Fig. 2 shows the instrumentation layout of sensors in three boreholes. The depths of moisture sensors were $0.9 \mathrm{~m}$ and $1.8 \mathrm{~m}$ in each of the boreholes, while the suction sensors were installed at a depth of $0.9 \mathrm{~m}$ in two of the boreholes. A hand auger was used to drill the boreholes in order to install the sensors in the native soil at desired depth. Afterwards, a hand-made device was utilized to place the sensors at the side of each borehole at designated depths. The boreholes were manually backfilled with excavated in-situ soil. These sensors were set to record hourly data using data loggers. 


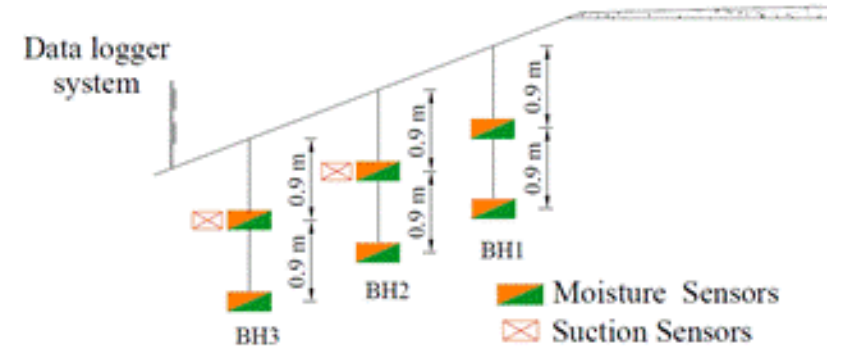

Fig. 2. Field instrumentation layout

The current study utilized Decagon 5TM (currently METER) moisture sensors and WP2 water potential probe for moisture and suction measurement, respectively. For data acquisition from sensors, EM 50 data loggers were used. Prior to field installation, the sensors were calibrated in the laboratory.

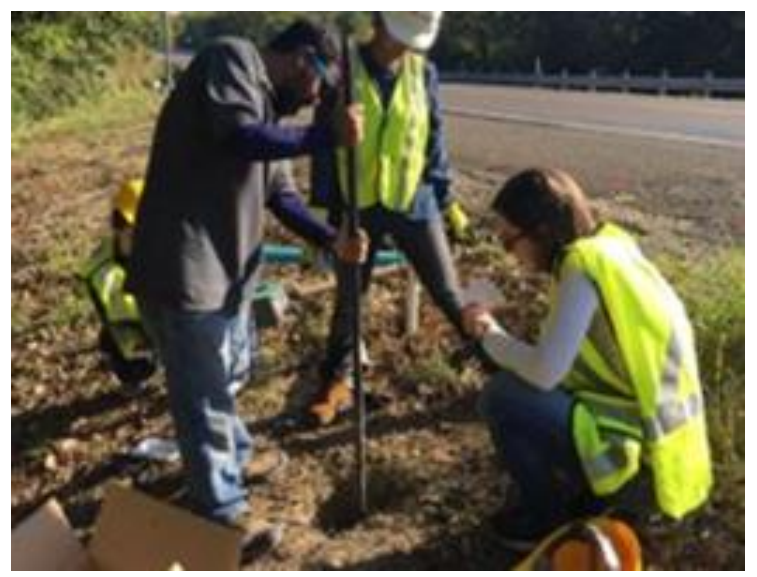

Fig. 3. Sensors installation at the study location

\subsection{SWCC Estimation}

As discussed earlier, soil water characteristic curve (SWCC) plays a vital role in modeling the behavior of soils in its unsaturated state. Although several laboratory methods for the determination of unsaturated soil parameters are available in the literature, the uncertainty in the results and the time required for test procedure has made it less desirable. Alternatively, empirical models developed over the years that correlate the basic soil properties to unsaturated soil parameters and estimate SWCC have gained popularity among researchers.

Many researchers have developed models in the form of mathematical equations by best fitting SWCC from experiments (Brooks \& Corey 1964 [13]; van Genuchten 1980 [14]; Fredlund \& Xing 1994 [15]). Leong \& Rahardjo (1997) [16] suggests that the model generating sigmoidal shape of soil water characteristic curves fits and performs better than other models. Studies have found that the soil water characteristic curve is not only dependent on suction but largely influenced by the past stress states as well $(\mathrm{Ng}$ \& Pang 2000 [17]; Pham \& Fredlund 2008 [18]). As such, attempts were also made to incorporate the change in void ratio and various other factors during SWCC estimation. From various models developed, van Genuchten (1980) [14] and Fredlund \& Xing (1994) [15] model showing sigmoidal SWCC are commonly used, and thus have been used in the current study.

Van Genuchten Model (1980) [14]:

$$
\theta=\theta_{r}+\frac{\theta_{s}-\theta_{r}}{\left[1+\left(\frac{\psi}{a}\right)^{n}\right]^{m}}
$$

where $\theta$ is volumetric moisture content at given state of suction $\psi ; \theta_{s}$ and $\theta_{r}$ are the saturated and residual volumetric water content, respectibely; and $\mathrm{a}, \mathrm{m}$ and $\mathrm{n}$ are fitting parameters.

Fredlund \& Xing (1994) [15]:

$$
\theta=C(\psi) \frac{\theta_{s}}{\left\{\ln \left[e+\left(\frac{\psi}{a}\right)^{n}\right]\right\}^{m}}
$$

and $C(\psi)$ is given by

$$
C(\psi)=1-\frac{\ln \left(1+\frac{\psi}{\psi_{r}}\right)}{\ln \left(1+\frac{1,000,000}{\psi_{r}}\right)}
$$

where $\theta$ is volumetric moisture content at given state of suction $\psi ; \theta_{s}$ and $\theta_{r}$ are the saturated and residual volumetric water content, respectively; and $\mathrm{a}, \mathrm{m}$ and $\mathrm{n}$ are fitting parameters which depends on air entry value, residual degree of saturation and rate of desaturation, respectively. Here, $C(\psi)$ is a correction factor that allows the soil moisture to become zero as the suction tends to reach $1,000,000 \mathrm{kPa}$.

Recent development and advancement in the field has simplified the estimation of SWCC by developing a model that correlates the basic soil properties directly to SWCC through regression analysis (Ellithy et al. 2012 [19]). Prediction models may be developed using four approaches that includes statistical estimation of water content at different suction values, correlating other soil properties with fitting parameters of equation to represent SWCC, physical based models and databases and neural networks (Zapata 2000 [20]; Johari et al. 2006 [21]). Prediction models have been reported to produce SWCC with a precision of $93 \%$ under laboratory conditions (Johari et al 2006 [21]); however, this needs to be verified in field where soil is not under controlled conditions. 


\subsection{Prediction Models}

In this paper, five prediction models have been utilized to extract SWCC of soil at field condition. These models use regression modelling approach to correlate basic soil properties to mathematical model. These models are described in the following section.

\section{$\underline{\text { Saxton et al (1986) Model [22] }}$}

This correlation equation was formulated by extending the work of Rawls et al (1982) [23]. The author used regression analysis to correlate the soil properties to parameters of mathematical equation. Brooks and Corey (1964) [13] general fit was used in the model for SWCC estimation which is as follows:

$$
\psi=A \Theta^{B}
$$

where $\mathrm{A}$ is given by

$$
A=\psi_{e} \theta_{S}^{-B}
$$

and $\mathrm{B}$ is curve fitting constant which correlates to the percent of clay and sand in the considered soil at a suction greater than $10 \mathrm{kPa}$.

Here, $\psi_{e}$ represents suction corresponding to air entry value (AEV). The author divided the curve into three separate portions with the first segment representing the state of the soil in its saturation to AEV, second from AEV to suction of $10 \mathrm{kPa}$ and the last one with suction greater than $10 \mathrm{kPa}$. The model was found to be satisfactory for the clay content in between the range of $10 \%$ to $60 \%$.

\section{Zapata et al. (2000) Model [24]}

This model determines SWCC from soil index properties using multiple regression. In total, 190 soils were used that consisted of 70 plastic soils and 120 non-plastic soils for the model development. This model was developed using $w$ and $P I$ for plastic soils and $D_{60}$ for non-plastic soils, where w indicates percent passing \#200, PI indicates the plasticity index of soil and $D_{60}$ is the particle size at which $60 \%$ of the material is finer.

\section{Aubertin et al. (2003) Model [25]}

This prediction model was modified after Kovacs (1981) [26]. This model utilizes void ratio and liquid limit for SWCC estimation.

\section{Perera et al. (2005) Model [27]}

This prediction model was developed after the work of Zapata et al (2000b) [28] using multiple regression and Fredlund and Xing (1994) [15] model. The correlation model was developed using grain size distribution for coarse grained soil and plasticity index for plastic soils or fine soils. In total, 154 non-plastic and 63 plastic soils were used for the model development.

\section{Ghanbarian et al (2010) Model [29]}

This model correlates the pore size distribution $(\lambda)$ of the Brooks and Corey (1964) [13] model to the fractal dimension, D of SWCC to predict parameter $\mathrm{m}$ in van Genuchten equation. The fractal dimension measures an index which represents the degree of accuracy with which the estimated model corresponds to the experimental data. The authors used two sets of data from unsaturated soil hydraulic database (UNSODA) and literature for the assessment of the developed approach.

\subsection{Field Based SWCC}

Alam (2017) [30]adopted the concept of developing field based SWCC from monitoring moisture and suction data. The author identified both laboratory and field based SWCC and found variations in the values. For example, the laboratory $\alpha, n$, and $m$ values were reported as $0.0031,1.6$, and 0.375 , respectively whereas the numbers obtained from field data were $0.02,1.52$, and 0.3421 respectively. As can be seen, the $\alpha$ value changed from 0.0031 to 0.02 which dictates the air entry value of soil. Another study by Alam et al. (2019) [31] reported that $\alpha$ parameter increased almost 41 times than the initial as-built condition. Moreover, Hedayati et al. (2020) [32] also reported field SWCC parameters from instrumented highway slope in Texas and reported better interpretation of soil behavior.

\section{Results and Discussion}

\subsection{Monitoring Results}

In the current study, real time moisture and suction values from one of the boreholes for the period of about 3 years ( 36 months) are analyzed. Both moisture and suction sensors are located at a depth of $0.9 \mathrm{~m}$ from surface. Fig.4 (a) and (b) show real time volumetric moisture content and suction against the observed rainfall events at the test site for the considered time period (October 2016 to September 2019). During this period, the volumetric moisture values fluctuated in between 0.161 to $0.441 \mathrm{~m}^{3} / \mathrm{m}^{3}$ while suction ranged from $-10 \mathrm{kPa}$ to $-1657.6 \mathrm{kPa}$ at $0.9 \mathrm{~m}$ depth. It is to be noted that the used suction sensor cannot measure values less than $-10 \mathrm{kPa}$. Similar pattern of variations were observed from the sensors at other locations as well.

It can be noted that, in addition to seasonal variations; the sensors reported instantaneous peak in response to rainfall events. The equilibrium moisture content value decreased in the summer time whereas it made a gradual rise in the wet season. For example, the average moisture content was around $30 \%$ in December 2017. The value was reported to be $20 \%$ in the following May 2018. Similar pattern was observed for the next cycle as well. The moisture sensors reported instantaneous peak from $2 \%$ to $22 \%$ from its previous value after precipitation events. At the same time, 
the suction sensors reported numbers more than $-1000 \mathrm{kPa}$ in three consecutive summer period. One interesting point to observe is that the suction sensors did not report instantaneous peaks or drops like the moisture sensors. This phenomenon will assist in developing the field based SWCC.

The analyzed data indicated a typical relationship between volumetric moisture content and field suction. The sensors maintained minimum possible suction value at the time of rainfall. In the other hand, significant moisture increase was recorded by the moisture sensors during that time span causing the soil to remain fairly saturated, especially in winter months as a result of prolonged rainfall. In contrast, considerably high suction was observed, which was as high as $-1657.6 \mathrm{kPa}$ in summer 2018 .

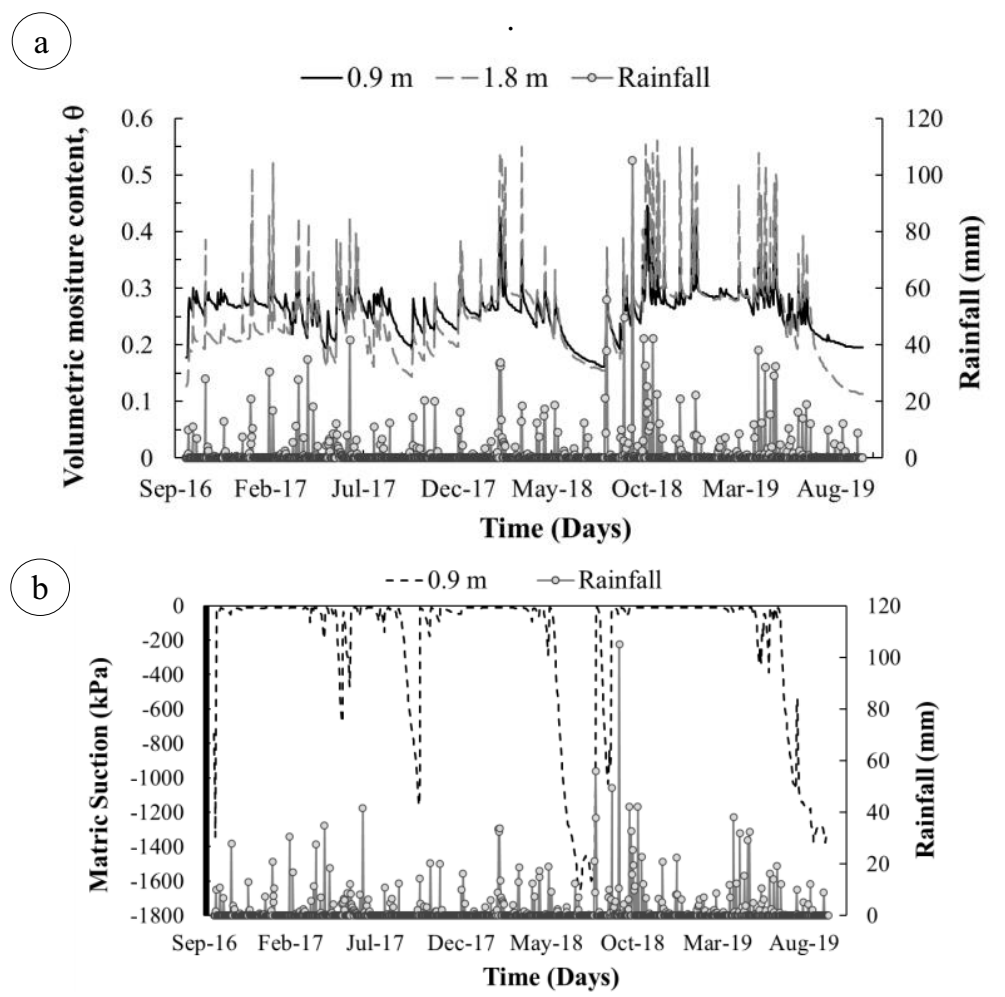

Fig. 4. Real time (a) volumetric moisture content (b) suction

\subsection{Generation of Field SWCC}

The instrumented moisture and suction sensors facilitated the measurement of field soil water characteristic curve (FSWCC). Fig 5 is plotted using the data from six moisture and two suction sensors . Hedayati et al. (2020) [32] produced several field SWCC graphs for several depths in a single highway slope. The sensors were located at various depths up to $15 \mathrm{ft}$. below the crest and middle part of a highway slope. As the location and depth of the sensors were close to each other, the authors produced one graph for field SWCC determination. In other words, low probability of variability of the data yielded one field SWCC graph. As can be noted, sensors' inability to go beyond $-10 \mathrm{kPa}$ in suction values created an almost vertical line along the $10 \mathrm{kPa}$ suction.
The plotted graph exhibited interpretable SWCC data from the field. As discussed earlier, field SWCC is not unique and rather characterized by the climatic conditions. After analyzing the data, two separate trends pointed out. Alam (2017) [30] adopted the upper bound, average, and lower bound approach in the field SWCC determination. The field generated curve was labelled as upper bound and lower bound graph to represent the hysteresis. The figure clearly demonstrates that the SWCC in the field does not follow a single path. The van Genuchten parameters a, $\mathrm{m}$, and $\mathrm{n}$ were estimated as 10 $\mathrm{kPa}, 0.152$, and 1.18 , respectively for upper bound curve whereas the lower bound curve yielded $4 \mathrm{kPa}, 0.31$, and 1.45 , respectively. The sensors were able to capture a real time suction vs moisture relationship which is dynamic in nature. The same static properties determined from laboratory SWCC testing was reported as $4 \mathrm{kPa}, 0.42$, 
and 1.74 respectively. These values can be considered as important indicators for water movement inside the soil. The $\mathrm{n}$ value indicates how quickly the water drains through the soil. Obviously, the $\mathrm{n}$ value is higher for sand as compared to clayey soils due to the difference in their permeability. The laboratory value of n (i.e.1.74) here is indicating a comparitive rapid movement of water whereas field upper value of $n$ (i.e. 1.18) is showing a slower movement. The field lower bound curve again reported a value of 1.45 in other season of the year. As can be seen from Fig. 5, the water movement will be higher in the summer time due to higher suction (lower bound curve) whereas it will be slow in wet season (upper bound curve) as the soil reaches its saturation value more frequently. This is a significant finding for the numerical modeling of pavement subgrade in various season of the year.

The authors reported only Van Genuchten parameters (Table 1) in this manuscript whereas similar output was observed for Fredlund and Xing parameters.

Table 1. Van Genuchten fitting parameters from field SWCC

\begin{tabular}{ccc}
\hline Parameter & Upper Bound & Lower Bound \\
\hline$\theta_{\mathbf{s}}$ & $0.395 \mathrm{~m}^{3} / \mathrm{m}^{3}$ & $0.355 \mathrm{~m}^{3} / \mathrm{m}^{3}$ \\
$\boldsymbol{\theta}_{\mathbf{r}}$ & $0.1 \mathrm{~m}^{3} / \mathrm{m}^{3}$ & $0.175 \mathrm{~m}^{3} / \mathrm{m}^{3}$ \\
$\boldsymbol{\alpha}$ & $0.1 \mathrm{kPa}^{-1}$ & $0.25 \mathrm{kPa}^{-1}$ \\
$\mathbf{n}$ & 1.18 & 1.45 \\
$\mathbf{m}$ & 0.152 & 0.310 \\
\hline
\end{tabular}

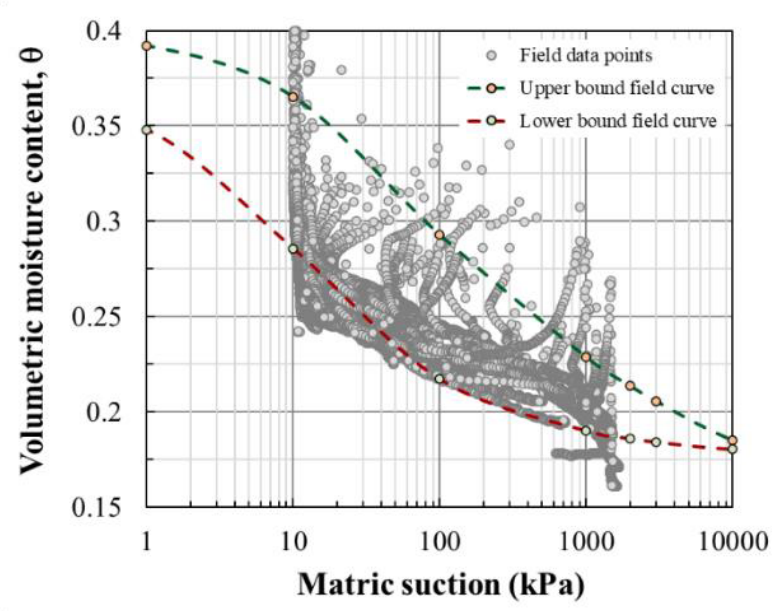

Fig. 5. Field SWCC fitted with van Genuchten equation showing upper and lower bound.

\subsection{SWCC Parameters from Predictive Models}

Fig. 6 compares generated soil water characteristic curve using five different prediction models. To generate these curves, basic soil properties such as particle size distribution and Atterberg limits were provided as an input in a spreadsheet provided by Elithy (2017) [33]. Among the utilized models, Ghanbarian et al. (2010) [29], which is a function of clay fraction, void ratio and saturated hydraulic conductivity generated the curve in close approximation to the field measured suction and moisture values and provided better fit than others.

Once the curve was extracted from each of these models, van Genuchten (1980) [14] and Fredlund and Xing (1994) [15] parameters were estimated by employing fitting algorithm. Table 2 and Table 3 summarizes the obtained parameters of the mathematical models, respectively.

The discrepancies in the obtained unsaturated parameters from different prediction models highlight the limitation of these models in accurately estimating the SWCC of soil at field conditions. This is because of various external factors that directly or indirectly affect the state of soil in field such as heterogeneity of soil layers, wetting and drying conditions, continuous change in stress state etc. which cannot be incorporated in through basic soil properties.

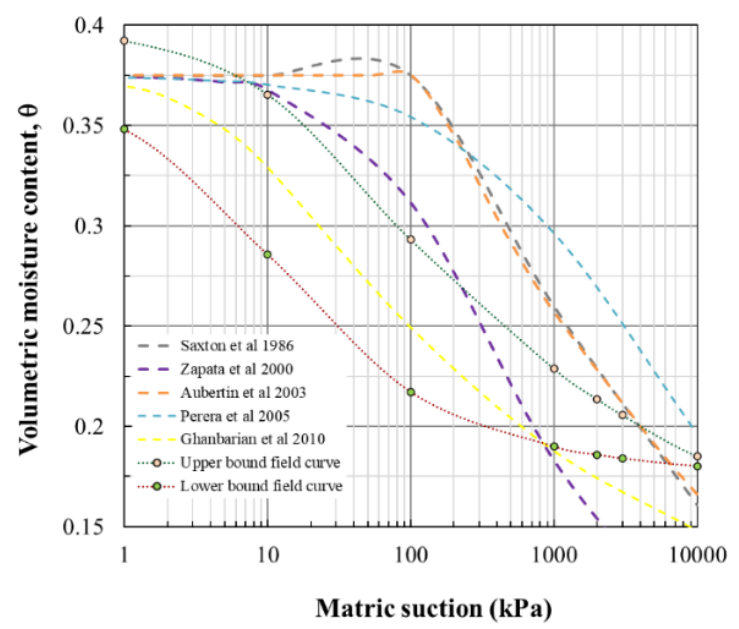

Fig. 6. SWCC generated using prediction models

Table 2. Estimated van Genuchten parameter from prediction

\begin{tabular}{|c|c|c|c|c|}
\hline \multicolumn{5}{|c|}{ models } \\
\hline Prediction Models & a (kPa) & $\mathbf{m}$ & $\mathbf{n}$ & $\theta_{\mathrm{r}}$ \\
\hline $\begin{array}{l}\text { Saxton et al (1986) } \\
{[22]}\end{array}$ & 500 & 0.286 & 1.4 & 0.075 \\
\hline $\begin{array}{l}\text { Zapata et al (2000) } \\
\text { [24] }\end{array}$ & 60 & 0.26 & 1.35 & 0.075 \\
\hline $\begin{array}{l}\text { Aubertin et al (2003) } \\
\text { [25] }\end{array}$ & 450 & 0.31 & 1.45 & 0.075 \\
\hline $\begin{array}{l}\text { Perera et al (2005) } \\
{[27]}\end{array}$ & 60 & 0.09 & 1.11 & 0.075 \\
\hline $\begin{array}{l}\text { Ghanbarian et al } \\
\text { (2010) [29] }\end{array}$ & 6.13 & 0.16 & 1.19 & 0.075 \\
\hline
\end{tabular}


Table 3. Estimated Fredlund and Xing parameter from prediction models

\begin{tabular}{lcccc}
\hline \multicolumn{1}{c}{ Prediction Models } & $\begin{array}{c}\mathbf{a} \\
\mathbf{( k P a})\end{array}$ & $\mathbf{m}$ & $\mathbf{n}$ & $\boldsymbol{\theta}_{\mathbf{r}}$ \\
\hline $\begin{array}{l}\text { Saxton et al (1986) } \\
{[22]}\end{array}$ & 300 & 0.4 & 2.8 & 0.075 \\
$\begin{array}{l}\text { Zapata et al (2000) } \\
{[24]}\end{array}$ & 70 & 0.7 & 1.5 & 0.075 \\
$\begin{array}{l}\text { Aubertin et al (2003) } \\
{[25]}\end{array}$ & 450 & 0.6 & 2.2 & 0.075 \\
$\begin{array}{l}\text { Perera et al (2005) } \\
{[27]}\end{array}$ & 200 & 0.5 & 0.9 & 0.075 \\
$\begin{array}{l}\text { Ghanbarian et al } \\
(2010)[29]\end{array}$ & 10 & 0.6 & 1 & 0.075 \\
\hline
\end{tabular}

The current study demonstrates the instrumentation conducted in expansive soil which experiences dessication crack during summer. These cracks accelerate the moisture movement affecting the soil moisture conditions in a real time scenario. This information was easily captured by the field installed sensors. On the other hand, incorporating basic soil index properties determined in the laboratory in SWCC prediction could not record this phenomenon. The parameter ' $a$ ' varied from 6 to $500 \mathrm{kPa}$ in various predictive models. Parameter ' $a$ ' is dependent on the AEV of the soil indicating when the water will start draining from the soil. A value of $500 \mathrm{kPa}$ is too high for clayey soil. It means the water will start transporting inside the soil after a suction value higher than $500 \mathrm{kPa}$. However, from field demonstration it was clearly observed to be around $10 \mathrm{kPa}$. Again, the parameter ' $\mathrm{n}$ ' describes the slope of the SWCC curve. The steeper the slope, the quicker the water will drain from the soil. The ' $n$ ' parameter variation was also found to be ranging from 1.1 to 1.45 in various models. The actual field captured values were different than the model predicted values. Due to variability of the values from various predictive models, it is very difficult for the geotechnical engineers to select one single predictve model. As such, it can be concluded that the field generated SWCC parameters provide more realistic and confirming values required for other analyses.

\section{Conclusion}

The study was conducted to evaluate the unsaturated parameters of soil through field instrumentation and prediction models. For this, sensors were installed at the side slope of State Highway 342 to capture real time moisture and suction variation in response to changing climatic conditions. The data was further analyzed to obtain field moisture vs suction relationship. The moisture vs suction data points from co-existing sensors were best fitted using prediction models and van Genuchten and Fredlund and Xing parameters were determined for transient seepage analysis. The following section summarizes the observation made in the current study:

1. Seasonal climatic variations can greatly alter soil moisture balance. The field instrumented results showed elevated average moisture in winter than in summer. Peaks and drops were observed due to rainfall events in both the periods.

2. The suction ranged in between $-10 \mathrm{kPa}$ to $-1657.6 \mathrm{kPa}$ during the monitoring period exhibiting huge spike in summer owing to increased temperature and less rainfall. Prolonged rainfall caused the suction to attain minimum value of $-10 \mathrm{kPa}$ during which the soil was found to be fully saturated.

3. The co-existing moisture and suction sensors in the field were able to capture more realistic soil hydraulic parameters which cannot be determined accurately in laboratories.

4. From among considered prediction models, only one model that is Ghanbarian et al (2010) [29] was found to best fit with the field obtained SWCC data points.

5. Field determined SWCC can better represent the soil moisture conditions in the field by capturing hysteresis due to drying and wetting and should be used for numerical modeling.

\section{References}

1. S. Gupta, A. Ranaivoson, T. Edil, C. Benson, \& A. Sawangsuriya. (2007). Pavement design using unsaturated soil technology.

2. D. G. Fredlund. (1996). The scope of unsaturated soil mechanics: An overview. In Proceedings of the First International Conference on Unsaturated Soils/Unsat'95/Paris/France/6-8 September 1995. Volume 3.

3. D. G. Fredlund, \& H. Rahardjo. (1993). Soil mechanics for unsaturated soils. John Wiley \& Sons.

4. H. Rahardjo, Y. Kim, \& A. Satyanaga. (2019). Role of unsaturated soil mechanics in geotechnical engineering. Int. J. Geotech. Eng.. 10 (1), 8.

5. N. Lu, \& W. J. Likos. (2004). Unsaturated soil mechanics. Wiley.

6. N. Lu, J.W. Godt, \& D. T. Wu. (2010). A closedform equation for effective stress in unsaturated soil. Water Resources Research, 46(5).

7. D. G. Fredlund, A. Xing, and S. Huang. (1994). Predicting the permeability function for unsaturated soils using the soil-water characteristic curve. Can. Geotech. J, 31(4), 533-546. 
8. M. Bordoni, M. Bittelli, R. Valentino, S. Chersich, \& C. Meisina. (2017). Improving the estimation of complete field soil water characteristic curves through field monitoring data.. J. Hydrol., 552, 283305.

9. J. D. Jabro, R. G. Evans, Y. Kim \& W. M. Iversen. (2009). Estimating in situ soil-water retention and field water capacity in two contrasting soil textures. Irrigation Science, 27(3), 223-229.

10. R. Al-Yahyai, B. Schaffer, F. S. Davies \& R. Munoz-Carpena. (2006). Characterization of soilwater retention of a very gravelly loam soil varied with determination method. Soil Science, 171(2), 85-93.

11. W. C. Dawson \& D. F. Reaser. (1990). Trace fossils and paleoenvironments of lower and middle Austin Chalk (Upper Cretaceous), north-central Texas.

12. Z. Abdi. (2014). Chemostratigraphy of the Austin Chalk and Upper Eagle Ford Shale, south central, TX. The University of Texas at Arlington.

13. R. H. Brooks \& A. T. Corey. (1964). Hydraulic properties of porous media. Hydrology papers (Colorado State University); no. 3.

14. M. T. Van Genuchten. (1980). A closed-form equation for predicting the hydraulic conductivity of unsaturated soils. Soil science society of America journal, 44(5), 892-898.

15. D. G. Fredlund \& A. Xing. (1994). Equations for the soil-water characteristic curve. Can. Geotech. J, 31(4), 521-532.

16. E. C. Leong \& H. Rahardjo. (1997). Review of soilwater characteristic curve equations. J. Geotech. Geoenviron. Eng., 123(12), 1106-1117.

17. C. W. Ng \& Y. W. Pang. (2000). nfluence of stress state on soil-water characteristics and slope stability. J. Geotech. Geoenviron. Eng, 126(2), 157-166.

18. H. Q. Pham \& D. G. Fredlund. (2008). Equations for the entire soil-water characteristic curve of a volume change soil. Can. Geotech. J, 45(4), 443-453.

19. G. S. Ellithy, F. Vahedifard, \& X. A. RiveraHernandez. (2012). Accuracy Assessment of Predictive SWCC Models for Estimating the van Genuchten Model Parameters. In PanAm Unsaturated Soils 2017 (pp. 1-10).

20. C. E. Zapata. (2000). Uncertainty in soil-watercharacteristic curve and impacts on unsaturated shear strength prediction.

21. A. Johari, G. Habibagahi, \& A. Ghahramani. (2006). Prediction of soil-water characteristic curve using genetic programming. J. Geotech. Geoenviron. Eng, 132(5), 661-665.

22. K. E. Saxton, W. Rawls, J. S. Romberger, \& R. I. Papendick. (1986). Estimating generalized soilwater characteristics from texture. Soil science society of America Journal, 50(4), 1031-1036.

23. W. J. Rawls, D. L. Brakensiek, \& K. E. Saxtonn. (1982). Estimation of soil water properties. Transactions of the ASAE, 25(5), 13161320.

24. C. E. Zapata, W. N. Houston, S. L. Houston, \& K. D. Walsh. (2000a). Soil-water characteristic curve variability. In Advances in unsaturated geotechnics (pp. 84-124).

25. M. Aubertin, M. Mbonimpa, B. Bussière \& R. P. Chapuis. (2003). A model to predict the water retention curve from basic geotechnical properties. Can. Geotech. J, 40(6), 1104-1122.

26. G. Kovács. (2011). Seepage hydraulics. Elsevier.

27. Y. Y. Perera, C. E. Zapata, W. N. Houston \& S. L. Houston. (2005). Prediction of the soil-water characteristic curve based on grain-size-distribution and index properties. In Advances in Pavement Engineering (pp. 1-12).

28. C. E. Zapata, M. W. Witczak, W. N. Houston, C. Richter, G. Larson, \& K. D. Walsh (2000b). Appendix DD-4: Improvement of the integrated climatic model for moisture content predictions. Guide for mechanistic-empirical design of new and rehabilitated pavement structures. TRB-NCHRP.

29. B. Ghanbarian-Alavijeh, A. Liaghat, G. H. Huang, \& M. T. Van Genuchten. (2010). Estimation of the van Genuchten soil water retention properties from soil textural data. Pedosphere, 20(4), 456-465.

30. M. J. B. Alam. (2017). Evaluation of Plant Root on the Performance of Evapotranspiration (ET) Cover System (Doctoral dissertation).

31. M. J. B. Alam, \& M. S. Hossain. (2019, March). Evaluation of Post-Construction Changes in Soil Hydraulic Properties through Field Instrumentation and In Situ Testing. In Geo-Congress 2019: Geotechnical Materials, Modeling, and Testing (pp. 722-732). Reston, VA: American Society of Civil Engineers.

32. M. Hedayati, A. Ahmed, M. S. Hossain, J. Hossain, \& A. Sapkota. (2020). Evaluation and comparison of in-situ soil water characteristics curve with laboratory SWCC curve. Transp. Geotech.., 100351.

33. G. S. Ellithy. (2017). Spreadsheet for estimating soil water characteristic curves (SWCC). Geotechnical and Structures Laboratory (US). 